Goldschmidt 2021 Abstract

https://doi.org/10.7185/gold2021.5756

\section{Microbial iron cycling during permafrost thaw}

\author{
CASEY BRYCE ${ }^{1}$, MONIQUE SÉZANNE PATZNER ${ }^{2}$, \\ CARSTEN W MUELLER ${ }^{3}$, MERRITT LOGAN ${ }^{4}$, ANNE \\ EBERLE $^{1}$, DANIEL STRAUB ${ }^{2}$, SARA KLEINDIENST ${ }^{2}$, \\ CARMEN HOESCHEN ${ }^{5}$, AMY MCKENNA ${ }^{6}$, MAXIMILIAN \\ R. BARCZOK ${ }^{7}$, CHELSEA E. SMITH $^{7}$, LAUREN E. \\ KINSMAN-COSTELLO ${ }^{7}$, ELIZABETH HERNDON ${ }^{8}$, \\ THOMAS BORCH ${ }^{4}$ AND ANDREAS KAPPLER ${ }^{2}$
}

${ }^{1}$ University of Bristol

${ }^{2}$ University of Tuebingen

${ }^{3}$ University of Copenhagen

${ }^{4}$ Colorado State University

${ }^{5}$ Technical University of Munich

${ }^{6}$ National High Magnetic Field Laboratory

${ }^{7}$ Kent State University

${ }^{8}$ Oak Ridge National Laboratory

Presenting Author: casey.bryce@bristol.ac.uk

Northern hemisphere peatlands store vast amounts of carbon, particularly in permafrost regions where low temperatures inhibit organic matter decomposition. With high latitudes warming faster than anywhere else on the planet, there is urgent concern about the impact of permafrost thaw on the stability of this carbon store. It has been shown that iron(III) (oxyhydr)oxides can trap organic carbon in soils overlying intact permafrost, which may limit carbon mobilization and degradation. However, controls on the stability of iron-carbon associations in permafrost peatlands and their response to warming temperatures are poorly understood.

We have extensively characterised the dynamic interactions between iron and carbon in a thawing permafrost peatland in Abisko, Sweden. Here, oxic palsa mounds with ice-rich cores are rapidly collapsing into acidic bogs before ultimately transforming to ice-free fen-type wetlands. We show that Fe(III) (oxyhydr)oxides trap significant quantities of organic carbon in areas of intact permafrost but that these iron-carbon associations break down during thaw. This is a result of $\mathrm{Fe}$ (III) (oxyhydr)oxide mineral dissolution by Fe(III)-reducing bacteria. These bacteria increase in abundance soon after thaw initiates in response to increased water saturation and more reducing conditions. Mineral dissolution at the point of permafrost collapse drives release of dissolved organic carbon and coincides with increased fluxes of greenhouse gases (carbon dioxide and methane) as well as a sharp increase in the abundance of methanogens and methanotrophs.

Permafrost thaw also increased abundance of $\mathrm{Fe}(\mathrm{II})$-oxidizing microorganisms. This suggests that post-thaw iron cycling is highly dynamic, and that measured iron redox state emerges from the net balance of reductive and oxidative processes. Indeed, seasonal re-precipitation of Fe(III) (oxyhydr)oxides was observed in some thawed areas. This work has greatly expanded our appreciation of microbe-mineral interactions in permafrost peatlands and reveals an important and previously over-looked role for iron-cycling microorganisms in influencing organic carbon stability and greenhouse gas emissions in one of Earth's most rapidly changing ecosystems. 